\title{
BMJ Open Association between periductal fibrosis and bile duct dilatation among a population at high risk of cholangiocarcinoma: a cross-sectional study of cholangiocarcinoma screening in Northeast Thailand
}

Nittaya Chamadol, ${ }^{1,2}$ Narong Khuntikeo, ${ }^{1,3}$ Bandit Thinkhamrop, ${ }^{1,4,5}$ Kavin Thinkhamrop, ${ }^{5}$ Apiporn T Suwannatrai, ${ }^{6}$ Matthew Kelly, ${ }^{7}$ Supannee Promthet ${ }^{4}$

To cite: Chamadol N, Khuntikeo N, Thinkhamrop B, et al. Association between periductal fibrosis and bile duct dilatation among a population at high risk of cholangiocarcinoma: a cross-sectional study of cholangiocarcinoma screening in Northeast Thailand. BMJ Open 2019;9:e023217. doi:10.1136/ bmjopen-2018-023217

- Prepublication history for this paper is available online. To view these files, please visit the journal online (http://dx.doi. org/10.1136/bmjopen-2018023217).

Received 4 April 2018 Revised 24 January 2019 Accepted 18 February 2019

Check for updates

(c) Author(s) (or their employer(s)) 2019. Re-use permitted under CC BY-NC. No commercial re-use. See rights and permissions. Published by BMJ.

For numbered affiliations see end of article.

Correspondence to Dr Kavin Thinkhamrop; kavith@kku.ac.th

\section{ABSTRACT}

Objectives To assess associations between periductal fibrosis (PDF) and bile duct dilatation (BDD) in

ultrasonography (US) screening of population at risk of cholangiocarcinoma (CCA) due to residence in an endemic area for Opisthorchis viverrini. CCA survival rates are low, and early identification of risk factors is essential. BDD is one symptom that can identify patients at risk of CCA. Detection of PDF by US can also identify at-risk patients, at an earlier stage of CCA development. Identification of association between PDF and BDD will inform screening practices for CCA risk, by increasing the viability of PDF screening for CCA risk.

Setting Nine tertiary care hospitals in Northeast Thailand. Design Cross-sectional study.

Participants Study subjects in the Cholangiocarcinoma Screening and Care Program (CASCAP) in Northeast Thailand. CASCAP inclusion criteria are all residents of Northeast Thailand aged $\geq 40$ years. Participants are recruited through CCA screening centres and through primary healthcare units. So far, 394026 have been enrolled.

Methods PDF and BDD were identified through US. PDF was categorised into three groups, PDF1, 2 and 3, depending on their high echo locality in the peripheral, segmental and main bile duct, respectively. Associations between PDF and BDD were determined by adjusted $\mathrm{OR}$ and $95 \% \mathrm{Cl}$ using multiple logistic regression.

Results BDD was found in $6.6 \%$ of PDF3, $1.7 \%$ of PDF2 and $1.4 \%$ of PDF1 cases. Among PDF cases, especially in PDF3, BDD was found in men more than in women ( $8.9 \%$ and $4.6 \%$, respectively). Compared with non-PDF, the association between PDF3 and BDD was highly significant (adjusted OR=5.74, 95\% Cl 4.57 to 7.21 , $\mathrm{p}<0.001)$.

Conclusions Our findings reveal that there is a relationship between PDF and BDD, which is associated with CCA. Therefore, PDF can also be an indicator for suspected CCA diagnosis through US.
Strengths and limitations of this study

The large size of the study population and its geographical distribution across Northeast Thailand are a significant strength.

- This is the first and largest screening programme for cholangiocarcinoma (CCA) in an area with the highest incidence in the world.

- CCA risk factors (periductal fibrosis and bile duct dilatation) were measured using ultrasonography by skilled radiologists.

- Demographic, and some health, data were self-reported leading to potential bias in measurement of liver fluke infection, praziquantel treatment and pre-existing medical conditions including hepatitis $B$, hepatitis $C$ and diabetes mellitus.

- Self-report could lead to prevalence underestimates due to the fact that subjects may not have been willing to disclose sensitive or personal information.

\section{INTRODUCTION}

Cholangiocarcinoma (CCA) and hepatocellular carcinoma (HCC) are ranked the most prevalent cancers in Southeast Asia. ${ }^{1-3}$ The early stages of CCA can manifest through obstructive jaundice, which is found in $30 \%$ of patients who are diagnosed with primary sclerosing cholangitis. ${ }^{4}$ Other liver disorders-fatty liver disease, cirrhosis and liver mass-are likewise recognised risk factors for both CCA and HCC. ${ }^{5-10}$ Suspected CCA cases can also be identified through the presence of bile duct dilatation (BDD), which can be identified in suspected CCA cases through ultrasonography (US) screening. ${ }^{11} 12$ A previous study demonstrated that US screening is highly sensitive in identifying CCA through confirmed incidences of BDD. ${ }^{13}$ However, on 
the detection and diagnosis of bile duct and liver disorders, it is often too late to save patients with CCA and HCC due to the rapid progression to advanced stages of hepatic carcinoma. ${ }^{14}$ As well, detection of BDD by US requires the services of specialist radiologists, who are generally available only in major hospitals, limiting access to screening. Thus, the best way to save a patient's life and prevent the likelihood of cancer development is through early, easily accessible, screenings to detect the risk factors that may lead to cancer among high-risk populations.

As well as BDD, there are several other indicators for CCA risk including well-accepted premalignant lesions such as biliary intraepithelial neoplasm and intraductal papillary neoplasm of the bile duct. ${ }^{1516}$ Periductal fibrosis (PDF) is another abnormality of the bile duct which has been used to identify people at risk of developing CCA. This hepatobiliary abnormality is particularly prominent among people infected with the liver fluke, Opisthorchis viverrini. ${ }^{17-21}$ This infection is caused by the consumption of raw or lightly fermented fish products and is one of the key risk factors for development of CCA in the region. PDF is caused by the thickening of the bile duct wall, along the periportal space. ${ }^{22}$

The relationship between PDF and CCA is indicated by the regular detection of PDF in confirmed CCA cases, and this has been particularly common in Northeast Thailand where $O$. viverrini is endemic and a leading potential cause of CCA. ${ }^{8}$ As a result of this relationship, US detection has been utilised to identify people with PDF as a risk group for CCA development. ${ }^{8} 202324$ Hepatobiliary abnormalities identified through ultrasound have been shown in other studies to correlate well with histopathological confirmation making US a valuable tool in early identification of these health issues. ${ }^{8}$ Importantly, PDF can be identified through US, but does not require the services of a specialist radiologist increasing the potential access to screening, and PDF can be detected earlier than BDD allowing more effective intervention.

The potential to detect the risk of CCA earlier and without the need for specialist radiologists, through the identification of PDF, may be an important breakthrough in reducing CCA incidence. So, both PDF and BDD have been recognised as indicators of CCA, ${ }^{817}$ but their relationship to one another has yet to be established or even studied in depth. Determining their relationship, such as learning if one precedes the other, may make a significant change in how we screen for CCA via US. Therefore, this study seeks to determine if there is an association between PDF and BDD among people at a high-risk CCA population in Northeast Thailand. The results of this work will clarify necessary directions towards early screening methodologies and appropriate cancer treatment.

\section{METHODS}

\section{Study design}

This study presents data collected from the Cholangiocarcinoma Screening and Care Program (CASCAP) in
Northeast Thailand. CASCAP is a prospective cohort study that is considered the first project for CCA screening in a high-risk population with a community-based bottom-up approach. ${ }^{25}$ Although this overall project is a prospective cohort study, the results presented here use cross-sectional data from the baseline study carried out with participants.

The overall aim of the study is to recruit all adults aged $\geq 40$ years who reside in Northeast Thailand and to screen them for CCA and its risk factors in terms of hepatobiliary abnormalities and infection with the liver fluke $O$. viverrini. As such, there are no strict inclusion or exclusion criteria apart from age group and place of residence. Once consent has been obtained, the participants will be enrolled in the programme. The primary place of recruitment for this cohort study were nine tertiary care hospitals in the Northeast of Thailand. These hospitals serve as the main source of affordable tertiary care for local people in the region. Subjects were recruited at these hospitals in two ways. First, the screening group comprised individuals who had attended the hospital for other reasons and were invited to receive ultrasound screening without evidencing any symptoms. The second group, the walk-in group, were individuals who were attending the hospital because of CCA symptoms and this group can then receive treatment. All participants were asked to join the project by signing a consent form. All CCA patients were diagnosed and treated according to routine, real-world clinical practice by participating hospitals. Patients were followed-up and provided with either clinical or palliative care depending on the stage of their disease. Treatment outcomes were recorded. Follow-up took place every 3-6 months depending on the patient's condition and unless scheduled otherwise.

\section{Study population}

Our study recruited subjects from among people who participated in the CASCAP project. These subjects form two groups (screening and walk-in). The screening group comprised people who have undergone routine US and who showed no symptoms that could be related to CCA. The walk-in group comprised people who come to the hospital with symptoms indicating CCA, which has been diagnosed with US. The subjects included in our study were only those enrolled in the CASCAP database from 2013 to 2017 with a total of 394026 subjects.

\section{Patient and public involvement}

The CASCAP project is a comprehensive screening and treatment programme for CCA. Members of the public were first involved in the research in two ways. First when members of the public attended a participating hospital for any reason, hospital staff would actively recruit them to the study. Village health volunteers also recruited participants while carrying out their work. A second group were those who already has some suspected symptoms and attended a hospital for screening at which point they were recruited into the study. The study participants were not directly involved in the design of the study. Participants 
will be contacted at least annually to be screened for CCA risk. Patients identified as having CCA will receive standard care for the condition through the project. For the screening procedures covered by this report, participants are informed of the purpose, outcomes and implications of these procedures.

\section{Main outcome and independent variables}

The primary outcome of this study was BDD which was categorised into two groups (no/yes). The independent variable of interest was PDF. We classify PDF into three categories (PDF1, 2 and 3) using a WHO standard methodology originally developed for use in the assessment of schistosomal periportal fibrosis (PPF) but which is also valid for the study of PDF given that PPF and PDF have the same ultrasound images of Increased Periportal Echo. ${ }^{26}$ We used only three of the five classifications utilised in this methodology since anatomically extrahepatic and intrahepatic bile ducts run in parallel to the portal vein in the periportal space, so the pathology of the bile duct should be detected first in the periportal space. This identification system has been validated by comparing US diagnoses with histopathologically proven cases of PDF with good agreement between the methods. ${ }^{8}$ Using this system, PDF is categorised based on the anatomical location of the intrahepatic and extrahepatic bile duct. PDF1 is defined as having a high echo in the wall of small bile ducts scattered in the liver in a starry sky pattern, PDF2 is a high echo along the segmental bile duct wall running parallel with the portal vein and PDF3 is a high echo along the main bile duct wall running parallel with the portal vein in the periportal space. ${ }^{19}$

Both BDD and PDF were diagnosed via US by radiologists from the CASCAP project, all of whom took part in a special training course for ultrasound examination including all criteria to diagnose hepatobiliary abnormalities. A teleconsultation system was also set up to confirm diagnoses from radiologists. Demographic characteristics of PDF and non-PDF subjects were the independent variables including gender, age, education levels, occupations, having a relative diagnosed with CCA, liver fluke infection, praziquantel (PZQ) treatments, smoking (current or previous), alcohol consumption (current or previous) and diagnosis with hepatitis B (HB), hepatitis C (HC) and diabetes mellitus (DM). All demographic characteristics listed above were collected via face-toface interview by interviewer from the CASCAP using questionnaire.

\section{Statistical analysis}

The demographic characteristics that were categorical data were summarised using frequencies and percentages (ie, gender, age groups, education levels, occupations, having a relative diagnosed with CCA, liver fluke infection, PZQ treatments, smoking history, alcohol consumption history and diagnosis with HB, HC, DM and PDFs). The continuous data, such as the age of the subjects, were summarised by their mean, SD, median, minimum and maximum range.

The prevalence of BDD was calculated and the percentage of the prevalence was computed based on a normal approximation to a binomial distribution. Bivariate analysis using simple logistic regression was performed to investigate the association between the independent factors listed above and BDD. They were determined by crude OR and their 95\% CI. Then, multivariable analysis using multiple logistic regression was carried out to investigate the association between PDF and BDD as determined by the adjusted OR and $95 \%$ CI. The final multivariate model was adjusted for all factors which previous studies have reported to be associated with the hepatobiliary disease: PDF, gender, age, education levels, occupations, having a relative diagnosed with CCA, liver fluke infection, $\mathrm{PZQ}$ treatments, smoking, alcohol consumption as well as diagnosis with $\mathrm{HB}, \mathrm{HC}$ and DM.

There were missing values for some variables due to unwillingness of some participants to answer some sociodemographic or health history questions or from errors in data collection. Missing values for most variables were rare with proportions missing $<3 \%$ of participants. The only variable with a significant proportion of missing values was that of previous liver fluke diagnosis $(n=211869)$, but this number includes those who had reported never having been tested for infection.

All test statistics were two-tailed, and a p-value $<0.05$ was considered statistically significant. All analyses were performed by using a statistical package, Stata V.15.

\section{RESULTS}

\section{Descriptive summary}

The demographic characteristics of subjects were presented as numbers and percentages. A total of 394 026 subjects who underwent US screenings for CCA were enrolled in our study. The subjects were all between the ages of 40 and 100 years old and reported a mean age of $54.92 \pm 9.03$ years. Of these, approximately two-thirds were women $(61.4 \%)$, and the majority of them completed primary school education level $(72.9 \%)$ and worked as farmers $(77.9 \%)$. About one-third (29.7\%) had ever used PZQ treatment, and about one-fourth $(21.3 \%)$ reported being a smoker or ex-smoker. As per the data of PDF diagnosis, $17.6 \%$ have positive diagnosis and the highest percentage was in subjects diagnosed with PDF1 (12.3\%) while only $0.6 \%$ had PDF3 (table 1 ).

\section{Prevalence of BDD}

From this study, the overall prevalence of BDD was reported to be $1.2 \%$. The highest prevalence of BDD was $6.6 \%$ from the PDF3 group under PDF. PDF1 and PDF2 subjects reported a low prevalence rate of only $1.4 \%$ and $1.7 \%$, respectively (table 2). Our study found that the prevalence of BDD occurring in PDF subjects was high in men than in women, particularly in PDF3 $(8.9 \%$ and $4.6 \%$, respectively) (figure 1). Meanwhile, we also found 
Table 1 Baseline demographic and clinical characteristics of subjects

\section{Gender}

$\begin{array}{lll}\text { Female } & 242115 & 61.4 \\ \text { Male } & 151866 & 38.6\end{array}$

Missing data $(n=45)$

Age group (years)

\begin{tabular}{|lll|}
\hline $40-44$ & 49281 & 12.9 \\
\hline $45-49$ & 71564 & 18.7 \\
\hline $50-54$ & 78428 & 20.5 \\
\hline $55-59$ & 69530 & 18.2 \\
\hline$\geq 60$ years & 114305 & 29.8 \\
\hline $\begin{array}{l}\text { Mean } \pm \text { SD } \\
\text { Median } \\
\text { (minimum:maximum) }\end{array}$ & $54.92 \pm 9.03$ & \\
\hline
\end{tabular}

Missing data $(n=10$ 918)

Education levels

\begin{tabular}{|c|c|c|}
\hline None & 6561 & 1.7 \\
\hline Primary & 286840 & 72.9 \\
\hline Secondary & 78090 & 19.9 \\
\hline Certificate/bachelor & 18632 & 4.7 \\
\hline Higher than bachelor & 3055 & 0.8 \\
\hline \multicolumn{3}{|l|}{ Missing data $(n=848)$} \\
\hline \multicolumn{3}{|l|}{ Occupation } \\
\hline Unemployed & 15582 & 4.0 \\
\hline Farmer & 306421 & 77.9 \\
\hline Labour & 32420 & 8.2 \\
\hline Own business & 13467 & 3.4 \\
\hline $\begin{array}{l}\text { Government official/state } \\
\text { enterprises }\end{array}$ & 13997 & 3.6 \\
\hline Others & 11335 & 2.9 \\
\hline \multicolumn{3}{|l|}{ Missing data $(\mathrm{n}=804)$} \\
\hline \multicolumn{3}{|c|}{ Relatives diagnosed with CCA } \\
\hline No & 319902 & 81.4 \\
\hline Yes & 73286 & 18.6 \\
\hline \multicolumn{3}{|l|}{ Missing data $(n=838)$} \\
\hline \multicolumn{3}{|l|}{ Liver fluke infection } \\
\hline No & 113178 & 62.1 \\
\hline Yes & 68979 & 37.9 \\
\hline \multicolumn{3}{|l|}{ Missing data $(\mathrm{n}=211869)$} \\
\hline \multicolumn{3}{|l|}{ Praziquantel treatment } \\
\hline None & 270183 & 70.3 \\
\hline One time & 84136 & 21.9 \\
\hline Two times & 18126 & 4.7 \\
\hline Three times & 5264 & 1.4 \\
\hline More than three times & 6414 & 1.7 \\
\hline Missing data $(\mathrm{n}=9903)$ & & \\
\hline
\end{tabular}

Continued

\begin{tabular}{|c|c|c|}
\hline Characteristics & No $(n=394026)$ & $\%$ \\
\hline \multicolumn{3}{|l|}{ Smoking history } \\
\hline No & 308776 & 78.7 \\
\hline Yes, current or previous & 83754 & 21.3 \\
\hline \multicolumn{3}{|l|}{ Missing data $(n=1496)$} \\
\hline \multicolumn{3}{|l|}{ Alcohol consumption history } \\
\hline No & 214495 & 54.6 \\
\hline Yes, current or previous & 178564 & 45.4 \\
\hline \multicolumn{3}{|l|}{ Missing data $(n=967)$} \\
\hline \multicolumn{3}{|l|}{ Hepatitis B } \\
\hline No & 382058 & 98.2 \\
\hline Yes & 6803 & 1.8 \\
\hline \multicolumn{3}{|l|}{ Missing data $(n=5165)$} \\
\hline \multicolumn{3}{|l|}{ Hepatitis C } \\
\hline No & 388114 & 99.8 \\
\hline Yes & 747 & 0.2 \\
\hline \multicolumn{3}{|l|}{ Missing data $(n=5165)$} \\
\hline \multicolumn{3}{|l|}{ Diabetes mellitus } \\
\hline No & 362296 & 93.2 \\
\hline Yes & 26565 & 6.8 \\
\hline \multicolumn{3}{|l|}{ Missing data $(n=5165)$} \\
\hline \multicolumn{3}{|l|}{ Periductal fibrosis } \\
\hline None & 324482 & 82.4 \\
\hline PDF1 & 48383 & 12.3 \\
\hline PDF2 & 18686 & 4.7 \\
\hline PDF3 & 2475 & 0.6 \\
\hline
\end{tabular}

CCA, cholangiocarcinoma; PDF, periductal fibrosis.

the number of BDD in PDF1 subjects was highest among people aged 55 years old (figure 2 ).

\section{Associations with BDD}

Bivariate analysis

The crude analysis using simple logistic regression found the variable with the strongest association to BDD to be PDF3 compared with non-PDF (OR=6.35, 95\% CI 5.40 to $7.46, \mathrm{p}<0.001)$. Other factors that were significantly associated with BDD included gender, with men being more affected by BDD than women; age, with a progressively increasing OR; lower education levels; occupation that was unemployed; infected liver fluke; PZQ used, with a progressively increasing OR; having a history of smoking and alcohol consumption; being positive for DM diagnosis (table 2).

\section{Multivariable analysis}

Through the multivariable analysis using multiple logistic regression, all factors were adjusted and the association of PDF3 subjects having BDD remained significantly high compared with non-PDF subjects (adjusted $\mathrm{OR}=5.74$, 
Table 2 Prevalence, and crude and adjusted odd ratios of BDD-associated factors and their $95 \% \mathrm{Cl}$

\begin{tabular}{lcllll}
\hline Factors & Subjects & \% BDD & Crude OR & Adjusted OR & $\mathbf{9 5 \%}$ Cl \\
\hline $\begin{array}{l}\text { Over all } \\
\text { Periductal fibrosis }\end{array}$ & 394026 & 1.2 & N/A & N/A & N/A \\
$\quad$ None & 324482 & 1.1 & 1 & 1 & \\
\hline PDF1 & 48383 & 1.4 & 1.23 & 1.25 & 1.11 to 1.40 \\
PDF2 & 18686 & 1.7 & 1.55 & 1.24 & 1.04 to 1.47 \\
PDF3 & 2475 & 6.6 & 6.35 & 5.74 & 4.57 to 7.21
\end{tabular}

Gender

$\begin{array}{llllll}\begin{array}{l}\text { Female } \\ \text { Male }\end{array} & 242115 & 0.9 & 1 & 1 & \\ \begin{array}{l}\text { Age group (years) } \\ 40-44\end{array} & 151866 & 1.7 & 2.00 & 1.46 & 1.31 \text { to } 1.63 \\ 45-49 & 49281 & 0.6 & 1 & 1 & \\ 50-54 & 71564 & 0.6 & 1.04 & 1.10 & 0.88 \text { to } 1.38 \\ 55-59 & 78428 & 0.9 & 1.44 & 1.42 & 1.15 \text { to } 1.75 \\ \geq 60 \text { years } & 69530 & 1.1 & 1.77 & 1.74 & 1.42 \text { to } 2.14 \\ & 114305 & 2.1 & 3.46 & 3.14 & 2.59 \text { to } 3.81\end{array}$

Education levels

\begin{tabular}{|c|c|c|c|c|c|c|}
\hline None & 6561 & 1.6 & 1 & 1 & & \\
\hline Primary & 286840 & 1.3 & 0.82 & 0.91 & 0.65 to 1.27 & \\
\hline Secondary & 78090 & 0.8 & 0.53 & 0.72 & 0.51 to 1.03 & \\
\hline Certificate/bachelor & 18632 & 1.1 & 0.71 & 0.81 & 0.53 to 1.24 & \\
\hline Higher than bachelor & 3055 & 1.5 & 0.98 & 0.94 & 0.52 to 1.71 & \\
\hline Occupations & & & & & & $<0.001$ \\
\hline Unemployed & 15582 & 2.5 & 1 & 1 & & \\
\hline Farmer & 306421 & 1.1 & 0.45 & 0.47 & 0.40 to 0.55 & \\
\hline Labour & 32420 & 1.0 & 0.39 & 0.53 & 0.41 to 0.67 & \\
\hline Own business & 13467 & 1.0 & 0.40 & 0.65 & 0.48 to 0.87 & \\
\hline Government/state enterprises & 13997 & 1.5 & 0.59 & 0.87 & 0.63 to 1.20 & \\
\hline Others & 11335 & 1.4 & 0.57 & 0.60 & 0.44 to 0.80 & \\
\hline Relatives diagnosed with CCA & & & & & & 0.018 \\
\hline No & 319902 & 1.2 & 1 & 1 & & \\
\hline Yes & 73286 & 1.2 & 0.99 & 1.12 & 1.02 to 1.24 & \\
\hline Liver fluke infection & & & & & & $<0.001$ \\
\hline No & 113178 & 1.2 & 1 & 1 & & \\
\hline Yes & 68979 & 1.5 & 1.24 & 1.25 & 1.12 to 1.39 & \\
\hline Praziquantel treatment & & & & & & 0.067 \\
\hline None & 270183 & 1.1 & 1 & 1 & & \\
\hline One time & 84136 & 1.3 & 1.20 & 0.85 & 0.75 to 0.95 & \\
\hline Two times & 18126 & 1.5 & 1.33 & 0.93 & 0.79 to 1.10 & \\
\hline Three times & 5264 & 1.7 & 1.56 & 1.10 & 0.85 to 1.43 & \\
\hline More than three times & 6414 & 1.8 & 1.63 & 1.26 & 1.00 to 1.59 & \\
\hline Smoking history & & & & & & $<0.001$ \\
\hline No & 308776 & 1.0 & 1 & 1 & & \\
\hline Yes, current or previous & 83754 & 2.0 & 2.11 & 1.31 & 1.17 to 1.46 & \\
\hline Alcohol consumption history & & & & & & 0.002 \\
\hline No & 214495 & 1.0 & 1 & 1 & & \\
\hline
\end{tabular}

Continued 


\begin{tabular}{|c|c|c|c|c|c|c|}
\hline Factors & Subjects & $\%$ BDD & Crude OR & Adjusted OR & $95 \% \mathrm{Cl}$ & $P$ value \\
\hline Yes, current or previous & 178564 & 1.4 & 1.45 & 1.17 & 1.06 to 1.29 & \\
\hline Hepatitis B virus & & & & & & 0.298 \\
\hline No & 382058 & 1.2 & 1 & 1 & & \\
\hline Yes & 6803 & 1.4 & 1.13 & 1.16 & 0.88 to 1.52 & \\
\hline No & 388114 & 1.2 & 1 & 1 & & \\
\hline Yes & 747 & 2.0 & 1.69 & 1.69 & 0.87 to 3.31 & \\
\hline Diabetes mellitus & & & & & & 0.011 \\
\hline No & 362296 & 1.2 & 1 & 1 & & \\
\hline
\end{tabular}

BDD, bile duct dilatation; CCA, cholangiocarcinoma; PDF, periductal fibrosis; N/A, not applicable.

$95 \%$ CI 4.57 to $7.21, \mathrm{p}<0.001$ ) (table 2). Compared with crude OR, the adjusted OR of gender, age, occupations, liver fluke infection, smoking history and alcohol consumption history, and a positive diagnosis of DM remained statistically significant, while a positive diagnosis of $\mathrm{HB}$ and $\mathrm{HC}$ remained non-significant (figure 3). Our study also found that relatives diagnosed with CCA changed from non-significant in bivariate analysis to significant in multivariable analysis, while education levels and PZQ treatment changed from significant to non-significant.

\section{DISCUSSION}

Liver cancer is one of the leading causes of death throughout the world. ${ }^{27} \mathrm{CCA}$ accounts for $>60 \%$ of these liver cancer cases with Northeast Thailand reporting the highest incidence in the world. ${ }^{28}{ }^{29} \mathrm{PDF}$ and BDD have been recognised as the key risk factors of CCA development. ${ }^{8} 1721$ Due to ambiguities in the relationship

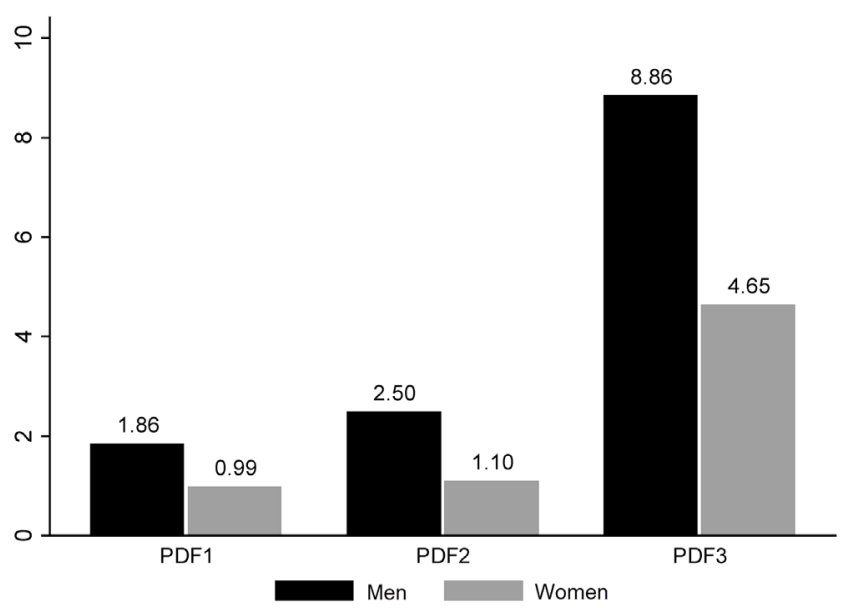

Figure 1 Percentage of BDD between men and women according to PDF1, 2 and 3. BDD, bile duct dilatation; PDF, periductal fibrosis. between PDF and BDD, our study investigated the prevalence of PDF and BDD in a high-risk CCA population to find if there was a presence of a statistically significant relationship between the two factors. Our study specifically found that the prevalence of BDD was significantly higher (6.6\%) among subjects who were diagnosed with PDF3 and it was the most statistically significant associated factor of BDD (adjusted OR=5.74, 95\% CI 4.57 to 7.21, $\mathrm{p}<0.001)$. Although a study conducted in Japan concluded fibrosis and BDD as being indicators of CCA, they did not mention an association between them. ${ }^{17}$ In addition, studies conducted in Thailand report only PDF as a major risk factor for CCA development. ${ }^{82130}$

We conducted a bivariate analysis via a simple logistic regression and found that gender, age and smoking history were the three most significant factors associated with BDD, and they remained significant in the multivariable analysis. The factor of relatives diagnosed with CCA became significant in multivariable analysis, but the magnitude of association was still relatively low, while education levels and PZQ treatment became non-significant. The

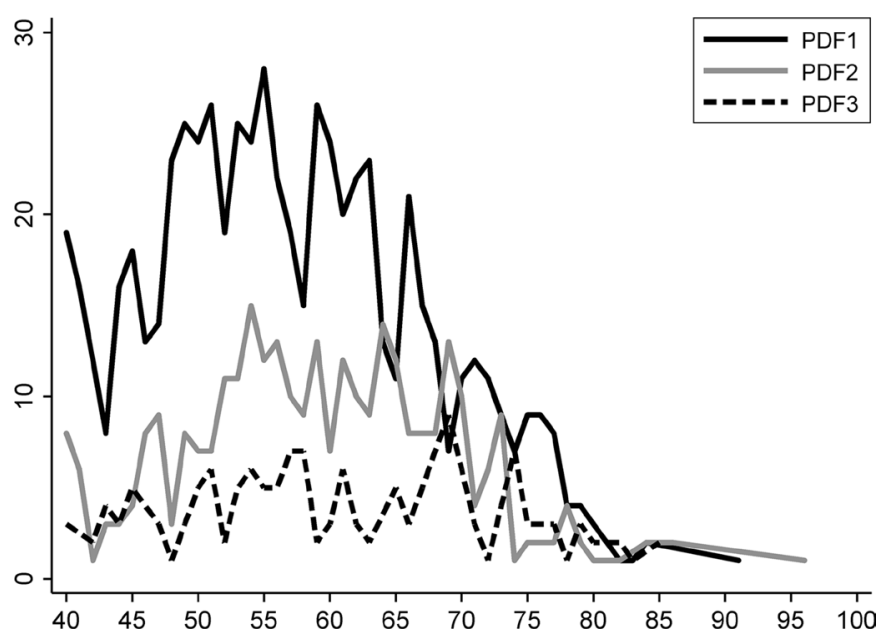

Figure 2 Number of BDD in PDF subjects by age range. BDD, bile duct dilatation; PDF, periductal fibrosis. 


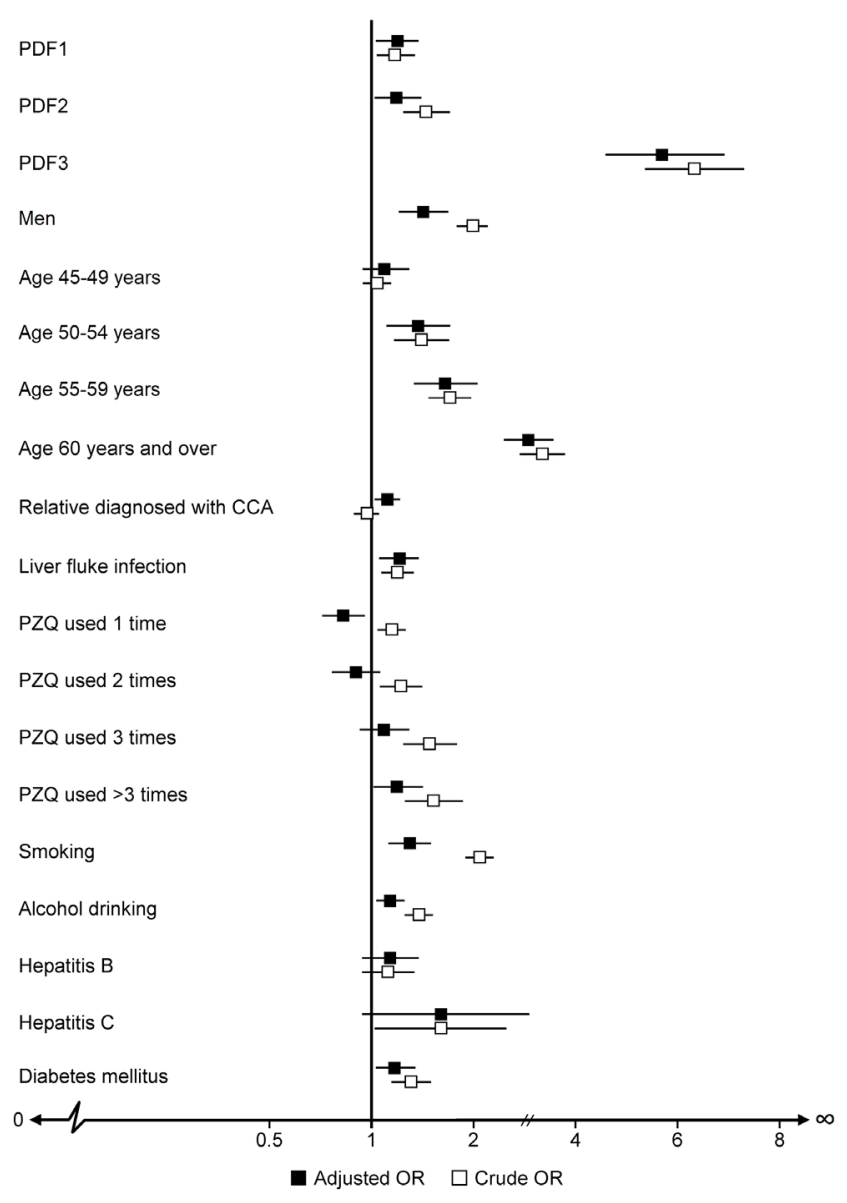

Figure 3 The adjusted OR and crude OR of the associated factors of BDD. BDD, bile duct dilatation; CCA, cholangiocarcinoma; PDF, periductal fibrosis; PZQ, praziquantel.

other factors that were statistically significant in the bivariate analysis but became less significant after adjusting for all factors in the multivariable analysis included occupations, alcohol consumption history, and being diagnosed with DM. Consistent with other studies, ${ }^{17-21}$ our results also found a significant association between current liver fluke infection and BDD. Liver fluke infection in Northeast Thailand mainly results from the consumption of raw or insufficiently fermented fish and is one of the main established risk factors for BDD and CCA development.

Our study found that those aged $\geq 60$ years are more likely to have BDD than other age groups. Meanwhile, our study also found the association of BDD increased with increasing age. We conclude that age plays a role in BDD development. This result is similar to a study conducted in Israel between 2001 and 2002, which found that bile duct size increases with age and reported age was positively correlated with bile duct size. ${ }^{31}$ A study from Canada in 2014 found that older age was associated with bile duct diameters, which increases with age. ${ }^{32}$ Therefore, it is not surprising that those who were in the oldest age group in our study had a strong association with BDD, which causes the bile duct to grow.
Subjects positive for $\mathrm{HB}$ and $\mathrm{HC}$ diagnosis demonstrated a non-significant association with BDD (adjusted $\mathrm{OR}=1.16,95 \% \mathrm{CI} 0.88$ to $1.52, \mathrm{p}=0.298$ and adjusted $\mathrm{OR}=1.69,95 \%$ CI 0.87 to $3.31, \mathrm{p}=0.124$, respectively). Our findings are close to the results reported by Barusrux and colleagues in 2012 which found that HB and $\mathrm{HC}$ were not related to CCA. ${ }^{33}$ However, it is also important to mention contradictory results reported in South Korea which found that HBV infection was a significant risk factor for intrahepatic cholangiocarcinoma (ICC) development with OR=2.3, 95\% CI 1.6 to $3.3 \mathrm{p}<0.050 .{ }^{34} \mathrm{HBV}$ infection was also related to a 3.4-fold risk of ICC in China. ${ }^{35}$ Another study conducted in Northeast Thailand in 2010 examined the association of $\mathrm{HB}$ and $\mathrm{HC}$ with CCA and reported a greater risk of $\mathrm{CCA}$ for those carrying the virus $(\mathrm{OR}=4,95 \% \mathrm{CI} 1.29$ to 16.44, $\mathrm{p}<0.05) .^{36}$

And interestingly, those who had CCA-diagnosed relatives had a higher association to BDD than those who did not have CCA-diagnosed relatives only $12 \%$ (adjusted $\mathrm{OR}=1.12,95 \%$ CI 1.02 to $1.24, \mathrm{p}=0.018)$. However, our results were consistent with Zhou et al, who identified genetic and familial risk factors as significantly contributing to the development of combined HCC-CCA through a bivariate analysis. ${ }^{37}$ It is worth mentioning that this significance could not be confirmed through a multivariable analysis. Other studies also demonstrate that having a family history of cancer is a significant associated factor for CCA development. ${ }^{38}{ }^{39}$ A risk factor study of CCA in Northeast Thailand also reported patients who had a family history of cancer were more likely to develop CCA than those without a family history of liver cancer. ${ }^{40}$ Death or traumatic incidences influence the decision-making process. This may be the reason behind the lack of association between family history of CCA and BDD in our statistical analysis. Perhaps, family members who experience a death of CCA-diagnosed family member are more likely to take measures to prevent the occurrence of a second CCA incidence in the family. A CCA traumatic experience may have served as a warning for family members to avoid this rapid and fatal outcome. These results reveal the complicated nature of understanding the true risk factors of CCA and pathogenesis to hepatic carcinoma in certain Asian societies.

This study has some limitations. First, although large, the study population is not representative of the overall population of Northeast Thailand. The recruitment method, through tertiary hospitals, may mean that the study population has some underlying differences in health status from the general population. In particular, the prevalence of BDD and PDF in the study group is likely to vary from overall population prevalence. However, the study has internal validity meaning relationships found between the various hepatobiliary abnormalities and other predictive factors are still important and useful. Also, many of the risk factors including history of previous liver fluke infection (and PZQ treatment) as well as health behaviours in terms of smoking and alcohol 
consumption were self-reported leading to some potential bias in their measurements.

PDF and BDD can be detected by ultrasound screening before any clinical symptom of CCA are evident. Additional further characterisation by other advanced imaging and endoscopic examinations is standard for differential diagnosis of CCA from other diseases. Histopathological confirmation is mandatory in patients with a surgical indication. Longitudinal data collection is necessary for further study of the relationship between PDF, BDD and CCA.

\section{CONCLUSIONS}

In conclusion, our key findings included identifying the factors associated with biliary tract disease in a highrisk population for CCA: PDF3, male gender, older age, having CCA-diagnosed relatives, infected liver fluke and smoking history. Based on our results, patients should be considered suspected-CCA cases during US screenings in high-risk areas through the detection of PDF, old age ( $\geq 50$ years), if they were infected for liver fluke, have CCA-diagnosed relatives, and are current or previous smokers. The interesting results regarding $\mathrm{HB}$ and $\mathrm{HC}$ diagnoses may need further evaluation and review due to some contradictions in the data. Greater consideration towards CCA and HCC prevention should be aimed at those in older age groups. Despite certain limitations, our data were based on a very large sample size and suggest a statistically robust association between PDF and BDD, specifically the PDF3 grouping. Early and routine screening of BDD and PDF may provide a means to reduce the incidence of liver-related diseases and CCA. Future planning of CCA surveillance should focus on early screening for both PDF and BDD.

\section{Recommendations}

This study was conducted in Northeast Thailand and may not reflect the general population. Further study is necessary in the region to test the generality of our results. Nevertheless, the methodology and results of our study can be used as a guideline in formulating clinical practice and future research priorities.

\section{Author affiliations}

${ }^{1}$ Cholangiocarcinoma Screening and Care Program (CASCAP), Khon Kaen University, Khon Kaen, Thailand

${ }^{2}$ Department of Radiology, Faculty of Medicine, Khon Kaen University, Khon Kaen, Thailand

${ }^{3}$ Department of Surgery, Faculty of Medicine, Khon Kaen University, Khon Kaen, Thailand

${ }^{4}$ Epidemiology and Biostatistics Section, Faculty of Public Health, Khon Kaen University, Khon Kaen, Thailand

${ }^{5}$ Data Management and Statistical Analysis Center (DAMASAC), Faculty of Public Health, Khon Kaen University, Khon Kaen, Thailand

${ }^{6}$ Department of Parasitology, Faculty of Medicine, Khon Kaen University, Khon Kaen, Thailand

${ }^{7}$ Department of Global Health, Research School of Population Health, Australian National University, Canberra, Australia

Acknowledgements We would like to acknowledge and thank Dr Malcolm Anthony Moore for his comments and suggestions over the final version of the manuscript.
Contributors NC, SP and KT conceived and designed this study. KT and BT performed the analysis. NC, SP, NK, BT, KT, ATS and MK wrote the manuscript. NC, NK, BT and KT collected the data and generated the clinical database. All authors have been involved in revising the manuscript and read and approved the final manuscript.

Funding The study was also supported by the Data Management and Statistical Analysis Center (DAMASAC), Faculty of Public Health, KKU, Thailand. This work was supported by KKU through CASCAP (Grant No. CASCAP 1/60), the National Research Council of Thailand through the Medical Research Network of the Consortium of Thai Medical Schools (Grant No. MRF.59-076) and National Research Council of Thailand (NRCT/2559-134).

Competing interests None declared.

Patient consent for publication Not required.

Ethics approval The research protocol was approved by Khon Kaen University Ethics Committee for Human Research, reference number HE591067.

Provenance and peer review Not commissioned; externally peer reviewed.

Data sharing statement No additional data are available.

Open access This is an open access article distributed in accordance with the Creative Commons Attribution Non Commercial (CC BY-NC 4.0) license, which permits others to distribute, remix, adapt, build upon this work non-commercially, and license their derivative works on different terms, provided the original work is properly cited, appropriate credit is given, any changes made indicated, and the use is non-commercial. See: http://creativecommons.org/licenses/by-nc/4.0/.

\section{REFERENCES}

1. Moore MA, Attasara P, Khuhaprema T, et al. Cancer epidemiology in mainland South-East Asia - past, present and future. Asian Pac J Cancer Prev 2010;11(Suppl 2):67-80.

2. Moore MA, Manan AA, Chow KY, et al. Cancer epidemiology and control in peninsular and island South-East Asia - past, present and future. Asian Pac J Cancer Prev 2010;11(Suppl 2):81-98.

3. Institue NC. Hospital based cancer registry annual report. Bangkok: Eastern Printing Public Company Limited PCL, 2012:157.

4. Rosen $\mathrm{CB}$, Nagorney DM, Wiesner $\mathrm{RH}$, et al. Cholangiocarcinoma complicating primary sclerosing cholangitis. Ann Surg 1991;213:21-5.

5. Songserm N, Promthet S, Sithithaworn P, et al. Risk factors for cholangiocarcinoma in high-risk area of Thailand: role of lifestyle, diet and methylenetetrahydrofolate reductase polymorphisms. Cancer Epidemiol 2012;36:e89-94.

6. Tao LY, He XD, Qu Q, et al. Risk factors for intrahepatic and extrahepatic cholangiocarcinoma: a case-control study in China. Liver Int 2010;30:215-21.

7. Shaib YH, El-Serag HB, Nooka AK, et al. Risk factors for intrahepatic and extrahepatic cholangiocarcinoma: a hospital-based case-control study. Am J Gastroenterol 2007;102:1016-21.

8. Chamadol N, Pairojkul C, Khuntikeo N, et al. Histological confirmation of periductal fibrosis from ultrasound diagnosis in cholangiocarcinoma patients. J Hepatobiliary Pancreat Sci 2014;21:316-22.

9. Welzel TM, Graubard BI, El-Serag HB, et al. Risk factors for intrahepatic and extrahepatic cholangiocarcinoma in the United States: a population-based case-control study. Clin Gastroenterol Hepatol 2007;5:1221-8.

10. Shaib YH, El-Serag HB, Davila JA, et al. Risk factors of intrahepatic cholangiocarcinoma in the United States: a case-control study. Gastroenterology 2005;128:620-6.

11. Hamilton SR, Aaltonen LA. Pathology and genetics of tumours of the digestive system. France: Lyon: IARC Press; Oxford University Press, 2000.

12. Khan SA, Davidson BR, Goldin RD, et al. Guidelines for the diagnosis and treatment of cholangiocarcinoma: an update. Gut 2012;61:1657-69.

13. Saini S. Imaging of the hepatobiliary tract. $N$ Engl J Med Overseas Ed 1997;336:1889-94.

14. Blechacz B, Gores GJ. Cholangiocarcinoma: Advances in pathogenesis, diagnosis, and treatment. Hepatology 2008;48:308-21.

15. Zen Y, Adsay NV, Bardadin K, et al. Biliary intraepithelial neoplasia: an international interobserver agreement study and proposal for diagnostic criteria. Modern Pathology 2007;20:701-9. 
16. Nakanuma $Y$, et al. Multistep carcinogenesis of perihilar cholangiocarcinoma arising in the intrahepatic large bile ducts. World $J$ Hepatol 2009;1:35-42.

17. Maetani $\mathrm{Y}$, Itoh $\mathrm{K}$, Watanabe $\mathrm{C}$, et al. MR imaging of intrahepatic cholangiocarcinoma with pathologic correlation. AJR Am J Roentgenol 2001;176:1499-507.

18. Institue NC. Guidelines for screening, diagnosis and treatment of liver cancer and cholangiocarcinoma. Bankok: National Office of Buddhism, 2011:81.

19. Chamadol N. Imaging in Cholangiocarcinoma. Khon Kaen, Thailand: Department of Radiology, Faculty of Medicine, Khon Kaen University, Khon Kaen, Thailand, 2014.

20. Xu HX, Chen LD, Liu LN, et al. Contrast-enhanced ultrasound of intrahepatic cholangiocarcinoma: correlation with pathological examination. Br J Radiol 2012;85:1029-37.

21. Sripa B, Mairiang E, Thinkhamrop B, et al. Advanced periductal fibrosis from infection with the carcinogenic human liver fluke Opisthorchis viverrini correlates with elevated levels of interleukin-6. Hepatology 2009;50:1273-81.

22. Benedetti NJ, Desser TS, Jeffrey RB. Imaging of hepatic infections. Ultrasound Q 2008;24:267-78.

23. Loria F, Loria G, Basile S, et al. RETRACTED ARTICLE: Contrastenhanced ultrasound appearances of enhancement patterns of intrahepatic cholangiocarcinoma: correlation with pathological findings. Updates Surg 2014;66:135-43.

24. Elkins DB, Mairiang E, Sithithaworn P, et al. Cross-sectional patterns of hepatobiliary abnormalities and possible precursor conditions of cholangiocarcinoma associated with Opisthorchis viverrini infection in humans. Am J Trop Med Hyg 1996;55:295-301.

25. Khuntikeo N, Chamadol N, Yongvanit P, et al. Cohort profile: cholangiocarcinoma screening and care program (CASCAP). BMC Cancer 2015;15:459.

26. Berhe N, Geitung JT, Medhin G, et al. Large scale evaluation of WHO's ultrasonographic staging system of schistosomal periportal fibrosis in Ethiopia. Trop Med Int Health 2006;11:1286-94.

27. Ferlay J, Soerjomataram I, Dikshit R, et al. Cancer incidence and mortality worldwide: sources, methods and major patterns in GLOBOCAN 2012. Int J Cancer 2015;136:E359-86.

28. Sripa B, Pairojkul C. Cholangiocarcinoma: lessons from Thailand Curr Opin Gastroenterol 2008;24:349-56.
29. Srivatanakul $P$, Sriplung $H$, Deerasamee S. Epidemiology of liver cancer: an overview. Asian Pacific journal of cancer prevention: APJCP 2004;5:118-25.

30. Prakobwong S, Yongvanit P, Hiraku Y, et al. Involvement of MMP-9 in peribiliary fibrosis and cholangiocarcinogenesis via Rac1-dependent DNA damage in a hamster model. Int J Cancer 2010;127:2576-87.

31. Bachar GN, Cohen M, Belenky A, et al. Effect of aging on the adult extrahepatic bile duct: a sonographic study. J Ultrasound Med 2003;22:879-82. quiz 83-5.

32. Landry D, Tang A, Murphy-Lavallée J, et al. Dilatation of the bile duct in patients after cholecystectomy: a retrospective study. Can Assoc Radiol J 2014;65:29-34.

33. Barusrux S, Nanok C, Puthisawas W, et al. Viral hepatitis B, C infection and genotype distribution among cholangiocarcinoma patients in northeast Thailand. Asian Pacific journal of cancer prevention: APJCP 2012;13(Suppl):83-7.

34. Lee TY, Lee SS, Jung SW, et al. Hepatitis B virus infection and intrahepatic cholangiocarcinoma in Korea: a case-control study. Am J Gastroenterol 2008;103:1716-20.

35. Li M, Li J, Li P, et al. Hepatitis B virus infection increases the risk of cholangiocarcinoma: a meta-analysis and systematic review. $J$ Gastroenterol Hepatol 2012;27:1561-8.

36. Srivatanakul $P$, Honjo $S$, Kittiwatanachot $P$, et al. Hepatitis viruses and risk of cholangiocarcinoma in northeast Thailand. Asian Pac J Cancer Prev 2010;11:985-8.

37. Zhou YM, Zhang XF, Wu LP, et al. Risk factors for combined hepatocellular-cholangiocarcinoma: a hospital-based case-control study. World J Gastroenterol 2014;20:12615-20.

38. Kamsa-Ard S, Luvira V, Pugkhem A, et al. Association between praziquantel treatment and cholangiocarcinoma: a hospital-based matched case-control study. BMC Cancer 2015;15:776.

39. Liu ZY, Zhou YM, Shi LH, et al. Risk factors of intrahepatic cholangiocarcinoma in patients with hepatolithiasis: a case-control study. Hepatobiliary Pancreat Dis Int 2011;10:626-31.

40. Manwong M, Songserm N, Promthet S, et al. Risk factors for cholangiocarcinoma in the lower part of Northeast Thailand: a hospital-based case-control study. Asian Pac J Cancer Prev 2013;14:5953-6. 
Correction: Association between periductal fibrosis and bile duct dilatation among a population at high risk of cholangiocarcinoma: a cross-sectional study of cholangiocarcinoma screening in Northeast Thailand

Chamadol N, Khuntikeo N, Thinkhamrop B, et al. Association between periductal fibrosis and bile duct dilatation among a population at high risk of cholangiocarcinoma: a cross-sectional study of cholangiocarcinoma screening in Northeast Thailand. BMJ Open 2019;9:e023217. doi: 10.1136/bmjopen-2018-023217

This article was previously published with an error.

Ethics reference number was incorrect. The correct number is HE551404.

Open access This is an open access article distributed in accordance with the Creative Commons Attribution Non Commercial (CC BY-NC 4.0) license, which permits others to distribute, remix, adapt, build upon this work non-commercially, and license their derivative works on different terms, provided the original work is properly cited, appropriate credit is given, any changes made indicated, and the use is non-commercial. See: http://creativecommons.org/licenses/by-nc/4.0/.

C Author(s) (or their employer(s)) 2019. Re-use permitted under CC BY-NC. No commercial re-use. See rights and permissions. Published by BMJ.

BMJ Open 2019;9:e023217corr1. doi:10.1136/bmjopen-2018-023217corr1

Check for updates 